\title{
Social Democracy, Complexity and Education: sociological perspectives from classical liberalism
}

\author{
Mark Olssen \\ University of Surrey
}

In the second half of the nineteenth century, in the period after John Stuart Mill, and into and including the first third of the twentieth century, a group of philosophers, sociologists, economists and journalists, systematically adapted classical liberal arguments to make them relevant to the appalling social conditions generated by the development of capitalism in the eighteenth and nineteenth centuries. Their writings contained distinctive models of society, of human nature, and of change, that are relevant to sociologists studying education in the twenty-first century. My aim throughout this chapter will be to work through the arguments of the new liberals accepting those that meet the tests of a critical interrogation as being relevant to twenty-first century global capitalism, and adapting or rejecting them as is appropriate. Although some of their arguments will be found wanting, I will argue that their original ideas in defence of social democracy can be restated in terms of developments in science and philosophy over a century since they wrote. Developments in post-quantum complexity theory, within both the physical and social sciences, will enable us to re-ground social democratic arguments and state them in a more plausible way for the twenty-first century.

\section{The sociology of John Atkinson Hobson}

In the last decades of the nineteenth and first decade of the twentieth century the economist John Atkinson Hobson advanced a justification for the welfare state complementing the contributions of T. H. Green and L.T. Hobhouse. In a way similar to Hobhouse's 'harmonic principle,' Hobson's analysis of individual and society was facilitated methodologically by the organic model of social structure. The organic model was analogical in that it likened society to a 'social organism'. In utilizing such an analogy Hobson invoked comparisons with the Hegel and German Idealism which created alarm amongst classical liberals. In developing his conception of the organic view, Hobson was influenced by John S. Mackenzie whose book An Introduction to Social Philosophy (2006), originally published in 1890, developed a coherent conception of the organic to challenge both the monadistic view (of classical liberalism and Leibniz) and the monistic view, which asserted the priority of the whole over the parts (Idealism). The organic view sees the individual as determined by social conditions. In this sense, the relation of individual to society is an 'intrinsic one' (p. 150). Society is not a mere aggregate of separate individuals, nor is it a mechanist (dualist) or chemical combination of them. The evidence that it is not a monistic system is that if that were the case, as society changed, so the parts would 
change almost simultaneously. This is not to say that there is not an aspect of the monadic, and an aspect of the monistic, which operate at different times and places, in different contexts, for there are mixed modes; just as complexity does not completely displace mechanism, but rather should be seen as supplementing or extending it. Further, although we are all penetrated and constituted by our surroundings this does not mean that we are all the same. As MacKenzie put it, there is no contradiction between social determinism and the independence of the individual:

That there is no contradiction between the independence which is now claimed for the individual and the fact of his social determination, becomes evident when we consider the nature of that determination and of that independence. That the individual is determined by his society, means merely that his life is an expression of the general spirit of the social atmosphere in which he lives. And that the individual is independent, means merely that the spirit which finds expression in him is a living force that may develop by degrees into something different (2006, p. 158).

Hobson's use of the organic metaphor is compatible with Mackenzie's and like Mackenzie's it has received stringent criticism. As R.N. Berki (1981, pp. 193-4) notes, Hobson was frequently characterised as an idealist and his idealism was "born of the endeavour to comprehend political reality in unitary terms." Although Hobson claimed to reject the monistic doctrine of Idealism, in that he rejected prioritising the force of the whole over the parts, he was idealist in the weaker sense that he still saw society as a unified whole. Such a whole in his sense was merely a system of interactions and unity was represented as not incompatible with difference. Besides, Hobson did not see unity itself of value, but recognised specific normative criteria drawing on Ruskin's concept of life as determining the conditions for inclusion and exclusion from the whole. The common good is thus represented by Hobson as a unified development of the whole society which contrasts from those aspects which are dysfunctional, evil, or represent what he termed, following Ruskin, illth. This is the sense that David Long detects idealism in Hobson's approach for he "idealistically condemned present arrangements for failing to come up to the standards of his rational ideal" (1996, p. 16).

Although not problem-free, Long concludes that "the organic analogy remains a useful start for a holistic analysis of society and Hobson's use of the analogy was certainly progressive for his time" $(1996$, p. 16). One must not expect too much from an analogical method of course. It must be seen, as is true for all analogies, as comprising both likenesses and unlikenesses. Human societies are in some ways like living things but in others not. For classical liberals, the analogy does not do justice to the issue of the claimed independence of individual consciousness. One can also criticize the analogical weighting given to uneven influence of the central organs over other parts of the body. Yet, in that it differentiates a particular form of unity from those types characteristic of monism, monadism, chemical integration, or mechanical solidarity, it presents a certain viability even given its analogical limitations.

One possible sense that the organic model can be criticised was its implications for conservativism. Although Hobson wrote against the politics of conservativism, John Allett (1990, p. 74) argues that "there is a significant conservative aspect to Hobson's 
thought." In Allett's view, "Hobson's conservativism is centred in his sociology" (p. 76). As he puts it:

Hobson's interest in conservativism is limited primarily to its usefulness as a corrective (not an alternative) to liberal individualism. There are occasions, however, when he engages in a kind of high moralizing about supra-individual forces of restraint that threatens to propel him beyond liberalism and its ultimate commitment to the self-directing personality.

The entailment of conservatism can not simply derive from the axiom of interdependence, or from the recognition of society as structure separate from its parts, but must reside in privileging unity or harmony above what is normatively required by life. While Hobson would have disputed any such charge, appealing to the independent normativity of his notions of life and illth, it may be that the model of organicism exerts, as Allett sees it, an independent pressure for unity and the status quo at the expense of justice or equality implied by a model of democratic socialism.

To the extent that the organic analogy coerces undue support for unity, I want to suggest that complexity theory can offer a more nuanced model in order to theorize the relations between individuals and social structures, as well as to theorize conception of causality, change, or evolution, creativity, originality, agency, and much else besides. Indeed, I will claim, it provides a revised model for social science, and especially for educational research. Although Hobson recognised certain complexity formulations, in most senses the organic analogy still conforms to the prevailing notions of Enlightenment science in its focus on closed, deterministic and integrable systems. In contrast, complexity theory represents a shift from matter-based to an energy-based physics, and offers a non-reductionist conception of the relationship between parts and whole which stresses the open nature of systems and where difference and unity are paired in a new and novel manner.

Complexity theories thus provide better models which enable an avoidance of conservative priority on unity or the status quo, do not prioritise the whole over the parts, or the spiritual over the material, and are compatible with recent post-quantum traditions in science as they have developed in the twentieth century. Although having roots in ancient Chinese and Greek thought, versions of complexity theory are a relatively new field of scientific enquiry, and are perhaps one of the most notable new developments since the advent of quantum theory in the early 1900s. Such theories are not only compatible with materialism, but are systemic, or holist, in that they account for diversity and unity in the context of a systemic field of complex interactional changes.

In his book Complexity and Postmodernism, Paul Cilliers (1998, p. viii) defines complexity in the following way:

In a complex system...the interaction constituents of the system, and the interaction between the system and its environment, are of such a nature that the system as a whole cannot be fully understood simply by analysing its components. Moreover, these relationships are not fixed, but shift and change, often as a result of self-organisation. This can result in novel features, usually referred to in terms of emergent properties. The brain, natural language and social systems are complex.

Cilliers presents a useful contemporary summary and update of complexity research. Complex systems interact dynamically in a non-linear and asymmetrical manner. Interactions take place 
in open systems through 'self-organisation' by adapting dynamically to changes in both the environment and the system. Self-organisation is an emergent property of the system as a whole. An emergent property is a property that is constituted due to the combination of elements in the system as a whole. As such it is a property possessed by the system but not by its components ${ }^{1}$. Cilliers (1998, p. 90) defines 'self-organisation' as "the capacity of complex systems which enables them to develop or change internal structure spontaneously and adaptively in order to cope with or manipulate the environment". Such systems are not in equilibrium because constantly changing as a consequence of interaction between system and environment, and as well as being influenced by external factors are influenced by the history of the system (1998, p. 66). Cilliers identifies social systems, the economy, the human brain, and language as complex systems ${ }^{2}$.

In the recent history of science, the work of Ilya Prigogine (1980, 1984, 1989, 1994, 1997, 2003) has advanced the field of post-quantum complexity analysis at the macroscopic and microscopic levels, based in non-equilibrium physics, linked to the significant work of the Solvay Institutes for Physics and Chemistry. Prigogine received a Nobel Prize in 1977. Like Nietzsche and others before him, he translated the effects of a theory of becoming, based on an Heraclitean idea of ceaseless change, providing a post-quantum understanding of the universe in terms of dimensions of chance, self-organisation, unpredictability, uncertainty, chaos, non-equilibrium systems, bifurication and change. Prigogine's central contribution was to non-equilibrium statistical mechanics and thermodynamics and the probabilistic analysis of dissipative structures (2003, pp. 45, 82). His main ideas (expressed nonmathematically) were that "nature leads to unexpected complexity" $(2003$, p. 8); that "selforganization appears in nature far from equilibrium" (p. vii); that "the universe is evolving" (p. 9); that the messages of Parmenides (that nothing changes) must be replaced by those of Heraclitus (that everything always changes) (pp. 9, 56); that "time is our existential dimension" (p. 9); that "the direction of time is the most fundamental property of the universe" (p. 64); that nothing is predetermined (p. 9); that non-equilibrium, timeirreversibility, feedback, non-integration, and bifurication are features of all systems, including evolution, which is to say that our universe is full of nonlinear, irreversible nondetermined processes (p. 59); that life creates evolution (p. 61, 65), and that everything is historical (p. 64) ${ }^{3}$. Writing over the same period as Michel Foucault ${ }^{4}$, he was concerned to analyse irreversible processes that generate successively higher levels of organisational complexity, where the complex phenomena are not reducible to the initial states from which they emerged. His work has been especially important for understanding changes within open systems $^{5}$, for theorizing time as a real dimension ${ }^{6}$, and for theorizing interconnectedness as a "characteristic feature of nature" $(2003, \text { p. 54) })^{7}$. Of especial relevance, his work theorizes the possibilities of chance as the outcome of system contingencies ${ }^{8}$.

Prigogine speaks highly about Henri Bergson. Although in his famous debate with Einstein, Bergson clearly misunderstood relativity theory, he was right about the issue of time, says Prigogine (2003, p. 61). For Bergson, time was a real dimension, and contrary to classical views, saw it as irreversible: "We do not think real time. But we live it, because life transcends intellect" (p. 46). The irreversibility of time dictates the impossibility of turning back, as well as the irreversibility of decisions and actions. The broader view is one of life and the universe as changing where time means creation and elaboration of novel and original patterns. It enables an understanding of how each individual is shaped by her society and yet unique. In such a conception where duration represents the real dimension of time:

consciousness cannot go through the same state twice. The circumstances may still be the same, but they will act no longer on the same person, since they find him at a new moment in his history. Our 
personality, which is being built up each instant with its accumulated experience, changes without ceasing. By changing, it prevents any state, although superficially identical with another, from ever repeating it in its very depth. That is why our duration is irreversible (1998, pp. 5-6).

New actions will take place at new times. Life changes constantly and new states are never precisely repeated in identical form. In drawing from Bergson, Prigogine (2003, p. 20) notes how such a thermodynamic vision once again makes individual agency pivotal. Independence develops not apart from the system, but in and through the system.

Such a complex analysis which retains a conception of individual agency within system parameters was also centrally important for Hobson. In order to give his theory normative anchorage, Hobson utilises a philosophy of life. It was certainly Hobson's normative vision to promote enhanced well-being and human welfare as central. In accord with life philosophy, it was Ruskin who gave Hobson his concept of social welfare. This involved redefining the concept of wealth a way from a concern with exchange, to a concern with its intrinsic worth, or as Allett $(1981$, p. 18) puts it, for its "life sustaining properties." In representing individuals as social beings, Hobson echoed the insights of Mackenzie who had written that "[i]t is only through the development of the whole human race that any one man can develop" (Mackenzie, 1890 , p. 180). This is a crucial theoretical axiom from the standpoint of educational analysis for it formulates the social democratic idea that it is the way we organise the society at large and its institutional structures that is so crucial for the development of each and every person. In such a view, the entire social democratic structure of society is a prerequisite for the application of liberal principles, for uneven development and social inequality negate the significance of liberal ideals such as freedom.

It was the inadequacy of representing individuals as solitary atoms that Hobson derived the central importance of social and institutional organisation. What frequently went unacknowledged was the assistance which individuals utilised in achieving their plans. To embark on a business initiative, for instance, presupposes sufficient acumen, skills, knowledge, resources, capital, and infrastructures, which presuppose their availability in institutional form. Production thus has a 'social element' underpinning it. So, too, does individual development, for each human being could only develop with various familial, educational, and community assistance. Once one acknowledges this, one sees that the development of adequate social structures is a prerequisite for individual development.

Progress for Hobson was concerned with enhancing well-being which exalted human welfare as the end or good to be sought after. For Hobson, welfare was a necessary social good. It is through his focus on welfare that he develops his economic philosophy concerned to develop the well-being of all of the international community and all humanity. Work was the medium through which individuals and societies would invest creative energy for production and progress. It was work that generated 'the power to sustain life.'

Hobson recognised that society was more than the separate individuals who comprised it and that classical liberalism could not adequately theorise the organic 
relations of individuals within society. It was based on such a view that he advanced his theory of surplus ${ }^{10}$. He theorized surplus as arising through organised cooperation which was essential to social and economic production. It is through cooperation that individuals produce more than is possible simply as a function of each individual contribution $^{11}$. Cooperation is thus a productive power in Hobson's theory, both productivity and well-being being increased by it.

It was from his theory of cooperation that Hobson developed his theory of underconsumption which has been his chief contribution to economic theory and was to have a major influence on Keynes. In his classic book co-authored with A. F. Mummery, The Industrial System, underconsumption is represented as the manifestation of dysfunctional economic development which distorts the system of the distribution of wealth and income by creating waste and inequality. Capitalism inherently supports a system of distorted development. The very process by which unproductive surplus was obtained, by business cunning and other strategies of deception, meant that the overall distribution and investment lacked any correlation with what the future of humanity required. Hobson proposed that a rational law of distribution would be in accord with human needs and capacities thus affirming an affinity with democratic socialism of a distinctively social democratic variety.

Underconsumption was a surplus of production and too little consumption. It was an economy with not enough spending. In Hobson's view, underconsumption results from three principal causes: overproduction, over-saving, and unequal distribution of surplus. It was the over-savings aspect that Keynes responded to. For Keynes' Hobson failed to distinguish savings from investment. In Keynes's theory, it was the distinction between savings and investment that became central to his break from neoclassical economics. Too much saving in his view resulted in too little investment, and hence the classical adage concerning the virtues of thrift were incorrect from the point of view of benefit to the community. It was for this reason the Keynes favoured public spending and government direction of investment to restore demand in aggregate spending, whereas Hobson advocated a more moral and political argument against unregulated capitalism.

Keynes can, in this sense, be seen as part of a tradition of social democratic thinking which developed from the 1870s to the 1930s. In his later life he acknowleged a great respect to Hobson's influence. His great contribution to social democracy was his appreciation of complexity dynamics as effecting outcomes which rendered traditional neoclassical conceptions of equilibrium effectively redundant. In this sense, he took Hobson's organic analogy, and rendered it more fittingly as a complexity model.

His conception of uncertainty was not seen as something which could be overcome, or which only operated in certain situations, but arose as a consequence of the complexity created by real time. Because individuals' actions in time created unique patterns it was theoretically impossible to predict or foretell future events. As he states:

We have, as a rule, only the vaguest idea of any but the most direct consequences of our acts....Thus the fact that our knowledge of the future is fluctuating, vague and uncertain, renders wealth a peculiarly unsuitable topic for 
the methods of classical economic theory....[A]bout these matters there is no scientific basis on which to form any calculable probability whatsoever. We simply do not know (Keynes, 1937, pp. 213-214).

Keynes proposed in The General Theory $(1953$, p. 152) that in such a situation the only recourse is reliance on rules or conventions as to how the economy ought to work in order to produce stability through institutional coordination. He thus incorporates post-quantum complexity themes avant la lettre. This is especially important in relation to his conception of real time which underpins his views on ignorance, uncertainty, and human agency. His conception of real time replaces the traditional Newtonian conception which characterized neoclassical economics as well as standard models of science. As O'Driscoll and Rizzo (1985) explain it, Newtonian time is spatialized, represented as a succession of points (continuous time), or line segments (discrete time) (p. 53), and is characterized by homogeneity, mathematical continuity and causal inertness (p. 54). For Bergson (1998, p. 338), change, or succession, is not real in the Newtonian theory. When it is conceived as a real addititive dimension, no matter how much action reproduces the patterns of the past, any future actions will be unique for the context of repetition will always vary.

It is this reconfiguration of time through the recognition of complexity that results in the emphasis on uncertainty in Keynes's work. Uncertainty also incorporates novelty, non-repeatability, and unpredictability, and also entails indeterminism in decisions. It thus asserts a thesis of creative human agency and imperfect foresight and knowledge. While creative decision-making is possible, it is in relation to a world that is not only unknown but unknowable. Hence the importance of ignorance means: "[ $t]$ he (perceived) unlistability of all possible outcomes" (O'Driscoll and Rizzo, 1985, p. 62). For Keynes, institutions while not eliminating uncertainty, attempt to control it. To see Keynes as a complexity management theorist broadens the scope and relevance of his insights from economics to politics, and from politics to education. For all institutions play a crucial role in sustaining life and achieving equilibrium of forces.

\section{Complexity and education}

Keynes arguments for the economy regarding uncertainty, risk, and ignorance, as the outcome of complex determinations are applicable outside of the economy narrowly defined, and can be seen to apply to other areas: welfare, various forms of assistance for disability and critical need; matters of urgency or crisis (floods, tornados, tsunamis, hurricanes, etc.); health, or education or training.

In this quest for complexity reduction education is a central institution, as was recognised by John Dewey, who explored the role and function of education in adapting to and coping with uncertainty in the environment. For Dewey, education was conceptualised not as a discipline-based mode of instruction in 'the basics' but according to a inter-disciplinary, discovery-based curricula defined according to problems in the existing environment. As Dewey says in Experience and Nature, "The world must actually be such as to generate ignorance and inquiry: doubt and hypothesis, trial and temporal conclusions...." (1929: p. 41). The rules of living and habits of mind represent a 'quest for certainty' in an unpredictable, uncertain and dangerous world (p. 41). For Dewey, the ability to organise experience proceeded 
functionally in terms of problems encountered which needed to be overcome in order to construct and navigate a future. In terms of learning theory, Dewey used the concept of 'continuity' in order to theorise the link between existing experience and the future based upon the "interdependence of all organic structures and processes with one another" (1929: p. 295). Learning for Dewey thus represented a cooperative and collaborative activity centred upon experiential, creative responses to contingent sets of relations to cope with uncertainty. As such, Dewey's approach conceptualizes part and whole in a dynamic interaction, posits the learner as interdependent with the environment, as always in a state of becoming, giving rise to a dynamic and forwardlooking notion of agency as experiential and collaborative. In such a model learning is situational in the sense of always being concerned with contingent and unique events in time.

Central to such a complexity approach, in that learning must deal with the uncertainty of contingently assembled actions and states of affairs, and by so doing it transforms itself from an undertaking by discrete individuals into one that is shared and collective activity. In terms of navigating a future in relation to economics, politics, or social decisions, it places the educational emphasis upon the arts of coordination. It is through plan or pattern coordination that institutions function and that a future is embarked upon. Because in planning one must assume incomplete information due to the dispersal of knowledge across social systems, such coordination can be more or less exact or loosely stochastic and probabilistic in terms of overcoming uncertainty. Because learning is time-dependent, and individuals and communities are always experiencing unique features of their worlds, uncertainty cannot be eliminated. Hence, all that is possible is pattern coordination in open-ended systems, where planning is formed around 'typical' rather than 'actual' features. Such plan or pattern coordination can only be a constructed order. Constructing plans becomes the agenda for education for life in Dewey's sense. Dewey ultimately held to the faith, as Keynes did, that despite unpredictability and uncertainty, the macro-societal (or macroeconomic) coordination of core social problems was possible.

Such a complexity approach is also pertinent for new research in the sociology of education for such approaches can contribute to the study of nonlinear dynamics in order to better understand schooling. Rather than view the social system in the image of traditional social science, inspired by Newtonian mechanics, as a linear system of predictable interactions, the approach of both Hobson and Keynes highlights the emergent character of social systems as self-organising non-linear and evolving systems characterised by uncertainty and unpredictability and emphasising both determinism and chance in the nature of events. What characterizes an emergent phenomena is that it it cannot be characterised reductively solely in terms of an aggregative product of the entities or parts of a system, understood through linear mechanistic causal analysis, in terms of the already known behaviours and natures of the parts, which are themselves ontologically represented as constants, but must be seen non-reductively in relation to their contingent self-organistion in terms of nonlinear dynamics as well as a theory of real time and of emergent phenomena. Schooling in such a view is characterised as a dynamic system whose states change with time through iteration, nonlinearity and self-organisation. Such an approach does not displace traditional mechanistic linear analyses such as those that assert correlations between social class and educational attainment but supplement them. It enables a more nuanced consideration of their variabilities. For the sociology of 
education this has the advantage of forging a new reconciliation of the micro-macro issues, enabling a theory of social life where levels of analysis between individual and group, as well as determinism and human agency, can be more accurately assessed. Its mission becomes that of describing and explaining the complexity of systems and their changes, starting from a conception of the whole, while avoiding an exclusive emphasis on atoms or sensations which characterised the old Newtonian paradigm. It offers the scope of supplementing linear mathematical analyses with non-linear mathematical or qualitative analyses for addressing issues of future concern. Theoretically, too, it enables a new approach to the modelling of social systems where the parts of a system interact, combine and modify or change in novel and unpredictable ways, and where the parts themselves may change in the process. In this, it enables us to better understand the role of individuals and of human agency in relation to systems, institutions, and cultural patterns; how decisions of the will may introduce into the course of events a new unexpected and changeable force; how the moral qualities of individuals can alter the course of history; and why, as some older sociological and philosophical approaches tended to maintain, such phenomena as the qualities of individuals, or actions in life, cannot be explained solely by general sociological laws of development, social class attributes, or cultural patterns. Although individuals are constituted by external social forces, given that time and space individuate those forces, the products of social evolution are inevitably unique and, in addition, through the exercise of imagination, choice operates to forge a conception of freedom quite compatible with the social production of selves. Such an account thus makes possible more historical forms of method where contingency (both dependent causality, mutability, and uncertainty), as well as novelty, free choice, creativity, and unpredictability become integral elements of the research approach and where top-down forms of deductive reasoning must be balanced by bottom-up analyses of individual or group agency and social interaction.

Finally, to conclude, we can also note that contemporary sociological approaches, such as that of Michel Foucault, contain complexity accounts of change of relevance for extending work in the sociology of education. Foucault's notion of dispotif, or apparatus, as a "strategic assemblage" enables a conceptualization of the school within a new pluralist reconciliation of part and whole simultaneously balancing the poles, as he calls them, of "individualization" and "totalization." For Foucault, the dispotif was defined as " a resolutely heterogeneous grouping comprising discourses, institutions, architectural arrangements, policy decisions, laws, administrative measures, scientific statements, philosophic, moral and philanthropic propositions, in sum, the said and the not-said, these are elements of apparatus. The apparatus is itself the network that can be established between these elements" (Foucault,1980: 194) In this conception, Foucault makes it clear that the apparatus permits a duality of articulation between discourse and material forms which varies contingently and operates in non-linear ways resisting linear, mechanical, causal explanations of the traditional Newtonian sort. It is in this sense that every form is a contingently expressed compound of relations between forces. Such multiple articulations are indeed essential to his idea of how an entity or construct constitutes its being in time, to his conception of historical change, as well as to his conception of strategy as a non-subjective intentionality; that is, as an order that cannot be reduced to a single strategist, or underlying cause or actor, but which nevertheless has intelligibility at the level of the society or institutions that emerges from an assemblage of heterogeneous elements, operating contingently and unpredictably within time and space. For 
Foucault, phenomena like sexuality, security and normalisation constitute such strategic assemblages. In such a model, as for Dewey, the school functions as a stabilizing mechanism which reduces or manages complexity constituting it as a variably and contingently constituted disciplinary strategy within life itself. Issues such as 'early school leaving', 'employability,' or 'the curricula' define the school as such a stabilizing institution concerned to adapt education to labour market requirements and citizens to society. In such a model the school is an institution that enables the navigation of an uncertain future.

\footnotetext{
${ }^{1}$ Other forms of emergentist materialism in western thought, see Bunge (1977), Haken (1977, 1990), Eve, Horsfall and Lee (1997).

${ }^{2}$ For another view of complexity theory, see Kauffman (1993, and 1995). Kauffman suggests that while events can be seen as having antecedent conditions which explain them, in open environments the possible combinations are unpredictable. Other characteristics of complex systems are that they do not operate near equilibrium; the relationships between components are non-linear and dynamic; elements do not have fixed positions; the relationships between elements are not stable; and there are always more possibilities than can be actualized.
}

${ }^{3}$ Prigogine mostly applies these ideas to physical systems, but does sometimes demonstrate their applicability to the social and human world. Discussing his theories of time and irreversibility, he notes how all events (e.g., "a marriage is an irreversible event" (2003: 67). The consequence of irreversibility is that "it leads to probabilistic descriptions, which cannot be reduced to individual trajectories or wave functions corresponding to Newtonian or Quantum mechanics" (p. 75).

${ }^{4}$ Prigogine's publications date from 1964 until shortly before his death in 2003.

${ }^{5}$ This involves a different description at the level of physics of elementary processes and a reversal of classical physics which saw systems as integrable, leading to determinism, and premised on time reversibility and equilibrium (as from Newton to Poincaré). Prigogine's approach replaces classical and Quantum mechanics in a concern for thermodynamics and probability and emphasizes variables such as noise, stochasticity, irreversibility. Such an approach suggests distinct limits to reductionism

${ }^{6}$ In this, he differs from Einstein who saw time as an illusion, as well as from classical mechanics.. He acknowledges debts to Bergson (Prigogine, 2003, p. 19-20); to Heidegger (2003, 9), and to Heraclitus (2003, p. 9, 10).

${ }^{7}$ Interconnectedness means that "individualities emerge from the global," and counters the idea that "evolution is independent of environment" (2003, p. 54).

${ }^{8}$ Pomian (1990) discusses issues such as determinism and chance in relation to Prigogine's work. Also see Prigogine (1997)

${ }^{9}$ Hobson adopted a number of Ruskin's phrases, and this is one of them. I cite from Long, 1996, p. 18.

${ }^{10}$ Surplus was either productive, through labour and cooperation, or unproductive, through rents, interests, or profit.

${ }^{11}$ Hobson gives the example of three persons building a boat to illustrate how through cooperation, each can contribute to something that individually they could not have produced (See Hobson, 1996, pp. 146-147).

References: 
Allett, J. (1990) 'The conservative aspect of Hobson's new liberalism', , in Michael Freeden (ed) Reapraissing J. A. Hobson: Humanism and Welfare. London: Unwin Hyman, pp. $74-99$.

Baier, A.C. (1991) A Progress of Sentiments: Reflections on Hume's Treatise.

Cambridge, Mass.: Harvard University Press.

Bergson, H. (1998) [orig, 1911] Creative Evolution. Trans. Arthur Mitchell, New York: Dover Publications.

Berki, R. N. (1981) On Political Realism. London: Dent.

Bunge, M. (1977). Emergence and the mind: commentary. Neuroscience, 2, 501-509.

Cilliers, P. (1998) Complexity and Postmodernism: Understanding Complex Systems. London: Routledge.

Dewey, J.(1929) Experience and Nature. New York: Dover Publications.

Eve, R.A., Horsfall, S. and Lee,M. E.(1997) Chaos, Complexity and Sociology:

Myths, Models and Theories. Thousand Oaks: Sage Publications.

Foucault, M (1980) The confession of the flesh. In C. Gordon (Ed.),

Power/Knowledge: Selected Interviews and Other Writings, 1972 - 1977 (pp. $194-$ 228). New York: Pantheon.

Haken, H. (1977). Synergetics - An introduction. Springer Series of Synergetics, 1. Berlin: Springer.

Haken, H. (1990). Synergetics as a tool for the conceptualization and mathematization of cognition and behaviour - How far can we go? In H. Haken \& M. Stadler (Eds), Synergetics of Cognition (pp. 2-31). Berlin: Springer.

Hobson, J. A. (1904) International Trade: An Application of Economic Theory. London: Methuen.

Hobson, J.A.(1996) The Social Problem. (Introduction by James Meadowcroft). Bristol:Thoemmes Press [reprint of the 1902 edition].

Hume, D. (1978) A Treatise on Human Nature, Second edition, Ed. P. H. Nidditch. Oxford: Claredon Press.

Kauffman, S. A. (1993) The Origins of Order: Self-Organisation and Selection in Evolution. New York: Oxford University Press.

Kauffman, S. A. (1995) At Home in the Universe; The Search for Laws of Complexity. London: Viking Press. 
Keynes, J.M (1937). 'The General Theory of Employment', Quarterly Journal of Economics 51 (2) February.

Keynes, J.M. (1953) [orig. 1936] The General Theory of Employment, Interest and Money. San Diego: Harcourt, Brace Javanovich Publishers.

Long, D. (1996) Towards a New Liberal Internationalism: The International TRheory of J.A. Hobson. Cambridge: Cambridge University Press.

Mackenzie, J.S. (2006) [orig. 1890] An Introduction to Social Philosophy. New York: Elibron Classics.

O’Driscoll, G.P. and Rizzo, M.J. (1985) The Economics of Time and Ignorance. Oxford: Basil Blackwell,

Pomian, K. (ed.) (1990) La querelle du determinisme. Philosophie de la science aujourd'hui. Paris: Gallimard/Le Debat.

Prigogine, I. (1980) From Being to Becoming, San Francisco: W.H.Freeman and Company.

Prigogne, I., and Stengers, I. (1984) Order Out of Chaos. New York: Bantam.

Prigogine, I. and Nicolis, G. (1989) Exploring Complexity. New York: W .H. Freeman.

Prigogine, I. (1994) Time, Chaos and the Laws of Chaos. Moscow: Ed. Progress.

Prigogine, I. (1997) The End of Certainty: Time, chaos and the new laws of nature.New York: The Free Press.

Prigogine, I. (2003) Is Future Given. New Jersey: World Scientific.

Swinney, H. L. (1983). 'Observations of order and chaos in nonlinear systems,' Physica, 7, pp. 3-16. 